\title{
SOBRE MORAL, DIREITO E DEMOCRACIA ${ }^{1}$
}

\author{
ALUISIO A. SCHUMACHER
}

$\mathrm{Na}$ fala cotidiana, o direito é freqüentemente apresentado como instrumento de opressão a serviço dos ricos e poderosos. Aparece também como domínio exclusivo de especialistas, advogados e juristas. Estamos habituados a não ver nenhuma relação entre direito e democracia, cuja estabilidade associamos a instituições de representação, eleições diretas regulares e sistemas partidários. Na universidade, essas duas áreas de conhecimento também se apresentam separadamente: o estudo do direito cabe à ciência jurídica, enquanto o problema da democracia está reservado à ciência política.

O objetivo deste artigo é contrariar esse estado de coisas. Partir do parentesco entre moral e direito, instituições sociais que desempenham a mesma função normativa básica: realizar a coordenação entre as ações de diferentes atores sociais, viabilizando a cooperação social; apresentar o direito moderno e suas principais funções na sociedade contemporânea e explicitar a relação entre direitos humanos e soberania popular, sugerindo que um depende do outro no que concerne à prática de autodeterminação democrática dos cidadãos.

O direito que nos interessa discutir aqui não é o sistema fechado reservado a especialistas, mas a instituição social aberta à moralidade que brota da sociedade. Esperamos com isso apoiar a compreensão de que, em certo sentido, também "produzimos" direito e, por isso, o grau em que ele funciona como instrumento de opressão ou de emancipação depende também de nossas práticas políticas e sociais e do uso que dele fazemos.

${ }^{1}$ Este texto foi elaborado para compor o Caderno Ética e Cidadania do projeto Pedagogia Cidadã. Agradeço a Alba Munari Schlesinger pela leitura atenta e contribuições, e aos colegas Juvenal Zanchetta Jr, Maria das Graças R. Moreira Petruci, Pedro Tosi e Teresa Malatian pelas sugestões. 
Dessa compreensão do direito, retiraremos implicações que convergem para não separar o jurídico do político. Trabalharemos para introduzir uma visão mais rica de democracia, a deliberativa ou participativa, não limitada à questão do regime político, mas conectada ao Estado de direito, isto é, ao grau de efetividade dos direitos da cidadania na sociedade. No interior dessa concepção, o direito aparece indissoluvelmente ligado à democracia, cujo desenvolvimento depende das condições de comunicação e procedimentos de formação da opinião e da vontade democráticas, únicas fontes de legitimação das leis e políticas governamentais.

A ligação proposta entre direito e democracia parte do seguinte pressuposto geral de qualquer sistema jurídico ocidental: todos os indivíduos são dotados de um grau básico de autonomia e responsabilidade. Premissa que torna

todo indivíduo uma pessoa jurídica, um portador de direitos e obrigações formalmente iguais não só no domínio político mas também nas obrigações contratuais, civis, criminais e tributárias, nas relações com órgãos estatais e em muitas outras esferas da vida social. Presume-se aqui que somos tão autônomos e responsáveis quanto as outras partes que realizam transações conosco. (O’Donnell 1998: 39)

Por isso, para garantir a autonomia das pessoas jurídicas, individual e/ou coletivamente consideradas, é que as constituições dos Estados-nação asseguram direitos humanos fundamentais. Muitos autores adotam o enfoque da autonomia para teorizar sobre a ligação entre direito e democracia. ${ }^{2}$ Aqui, vamos nos orientar basicamente pela reconstrução do direito e da democracia proposta por Habermas (1996). Com base em modelo derivado do uso da linguagem, desenvolvido a partir de 1970, esse autor propõe, nos anos 1980, uma ética da comunicação que, nos anos 1990, incorpora um procedimento democrático e proporciona base para a justificação dos direitos. Em vez de recorrer a abordagens derivadas da idéia do contrato social entre indivíduos racionais isolados, Habermas liga a interpretação e a validação dos direitos à anuência

2 Dahl (1989), Dworkin (1999), Held (1987) e muitos outros. Especificamente, sobre o tema da constituição do sujeito autônomo moderno, Taylor (1985 e 1989). 
democrática. ${ }^{3}$ Vejamos inicialmente alguns aspectos que aproximam e afastam direito e moral enquanto instituições sociais.

\section{MORALE DIREITO: FUNÇÃO SIMILAR E MEIOS DIFERENTES}

Para apresentar a função normativa comum à moral e direito, pensemos numa sociedade sem nenhum tipo de autoridade pública, isto é, sem tribunais nem legisladores, onde o controle da vida social se exerceria somente pela atitude geral do grupo em relação a seus próprios modelos de comportamento. Em tal contexto, práticas contrárias às expectativas sociais poderiam ser objeto de desaprovação. Assim, determinadas expressões faciais ou modalidades de linguagem corporal, com o uso, poderiam se consagrar como maneiras de censurar comportamentos, sendo aprendidas e mantidas de geração em geração.

Com o tempo, essas modalidades sociais de reprovar comportamentos poderiam converter-se em uma estrutura de regras primárias ou de obrigação. Isto é, de regras fundamentais prescrevendo ou determinando a realização ou a abstenção de certos tipos de comportamento; ou, ainda, de regras impondo determinadas obrigações.

É claro que nossa ilustração só se refere a uma dimensão restrita do que se entende por moral. Nada dissemos a respeito de atitudes e sentimentos individuais em relação a outros sujeitos, nem tampouco sobre a responsabilidade do indivíduo em relação a seu próprio comportamento. $\mathrm{Na}$ verdade, estamos somente introduzindo as origens da moral e do direito enquanto instituições sociais construídas pelos próprios sujeitos. E, nesse sentido, nos referindo a práticas e maneiras de fazer coisas que, diferentemente de instintos, têm de ser aprendidas.

Para que uma sociedade possa viver exclusivamente sob o império de tais regras primárias, explica Hart (1961: 89-90), algumas condições precisam ser preenchidas. Em primeiro lugar, as regras devem compreender restrições à liberdade de recorrer à violência, ao roubo e à fraude, tentações que os seres humanos devem poder dominar, para coexistirem em relação de vizinhança. Em sociedades primitivas, tais regras aparecem juntamente com outras, que impõem aos indivíduos obrigações

\footnotetext{
${ }^{3}$ A ética da comunicação de Habermas adota o seguinte princípio nuclear: "são válidas as normas de ação às quais todos os possíveis atingidos poderiam dar seu assentimento, na qualidade de participantes de discursos (comunicações) racionais" (Habermas 1996: 107).
} 
de prestar serviços ou contribuir para a vida em comum. Além disso, mesmo que a sociedade aqui concebida já possa apresentar uma tensão entre os que aceitam as regras e os que as rejeitam, a não ser quando o receio da pressão social lhes conduza a se conformar, o segundo grupo tem de ficar restrito a uma minoria. Do contrário, organizada de modo tão pouco rígido e com seus membros possuindo mais ou menos a mesma força, a sociedade concebida em nosso exemplo não se manteria.

Parte importante dessas regras primárias, lembra Haydon (1999: 31-32), tenderia a auxiliar os negócios da comunidade, protegendo seus membros contra a vulnerabilidade em face de perigos externos, bem como em relação a outros membros da mesma sociedade. Assim, se a comunidade emprega armas para caçar, é razoável supor a existência de normas para mantê-las em condições de uso. Além disso, na medida em que armas de caça podem ser potencialmente letais a membros do grupo, esses também devem ter elaborado normas sobre seu uso correto e segurança. Durante a caça, o comportamento de coordenação das ações dos membros do grupo e a cooperação resultante seriam vitais, pois sua ausência poderia implicar fome para a comunidade.

A existência de tais regras faz sentido sem a necessidade de introduzir qualquer distinção entre moral e direito. Nesse contexto, as crianças também aprenderiam que determinadas práticas são admitidas, enquanto outras não. E, isso, bem antes de terem clareza acerca das conseqüências que a violação das regras traz, no mundo dos adultos, para os sujeitos sociais.

Boa parte do quadro esboçado vale também para a educação em uma sociedade moderna e complexa como a que vivemos. A partir de expectativas de comportamento, as crianças aprendem, ainda hoje, práticas e maneiras de se comportar. Também aprendem que certas coisas não devem ser feitas. Passam a vivenciar e empregar expressões como 'deve' 'não deve', 'pode' 'não pode' e 'certo' 'errado', noções que reconhecem bem antes da apreensão dos termos 'moral'e 'direito' e da diferença entre o 'moralmente incorreto'e o "juridicamente incorreto".

Chegamos assim à noção de que qualquer sociedade necessita de uma estrutura básica de regras sustentadas e comunicadas de geração à geração. Estrutura essa anterior à própria distinção entre moral e direito. No entanto, só uma pequena comunidade - estreitamente ligada por vínculos de parentesco, crenças e sentimentos comuns e dotada de um meio ambiente estável - poderia viver com sucesso sob tal regime de regras que não emanam de nenhuma autoridade. Na ausência dessas condições, três 
tipos de dificuldades emergiriam (Hart 1961: 89-90):

a) A incerteza. Se surgirem dúvidas quanto às regras que devem ser usadas em determinado caso ou mesmo com respeito ao alcance de alguma regra, não haveria procedimentos para dirimi-las, tais como a referência a um código (texto) obrigatório ou a uma autoridade cujas decisões têm força obrigatória. Esses dois elementos, código e pessoas dispondo de autoridade, já pressuporiam a existência de regras com características diferentes das primárias. A essa dificuldade que atinge a estrutura social elementar baseada em regras primárias, denomina-se incerteza.

b) O caráter estático das regras. Em sociedades simples como a do nosso exemplo, mudanças nas regras só ocorreriam muito lentamente: através de um processo de desenvolvimento no qual linhas de conduta, inicialmente facultativas, tornam-se habituais e depois obrigatórias. Por meio de processo inverso, de caducidade ou desuso, os desvios, antes severamente punidos, passam a ser tolerados e na seqüência não mais percebidos. Em tal contexto social não seria possível adaptar deliberadamente as regras às circunstâncias, eliminando regras antigas e/ou introduzindo regras novas. Isso pressuporia, novamente, regras diferentes das primárias.

c) A ineficácia da pressão social difusa. Quando não há pessoas especialmente habilitadas para constatar, de modo irrevogável e obrigatório, o fato da violação das regras, as controvérsias relativas à questão de saber se determinada regra foi ou não transgredida aparecerão constantemente. Por isso fala-se que, na falta de tais agentes habilitados, a manutenção das regras só se dá por uma pressão social difusa, exercida pelos próprios interessados.

Para sanar essas três dificuldades, inerentes àquela forma elementar de estrutura social, as regras primárias, que obrigam a realização ou abstenção de certos comportamentos, têm de ser apoiadas por regras secundárias. Regras prescrevendo que homens e mulheres possam, ao realizar certos atos ou pronunciar determinadas palavras, introduzir novas regras, abolir ou modificar antigas; determinar a incidência de regras ou controlar sua implementação e operação. Enquanto as regras primárias impõem obrigações, as secundárias conferem poderes públicos ou privados e determinam a maneira pela qual as primeiras podem ser identificadas, promulgadas, derrogadas ou modificadas, além de estabelecerem definitivamente o fato de sua violação.

A introdução de maneiras de lidar com essas dificuldades pode ser considerada como um caminho que vai de um mundo pré-jurídico a um mundo jurídico. O direito vem complementar a fraqueza da moral nos três 
aspectos acima tratados, mas a moral continua a exercer pressão sobre o direito, suas normas e decisões, através de impulsos normativos que provêm da sociedade.

Para combater a primeira dificuldade, a incerteza, Hart (1961: 92-3) esclarece que o remédio é proporcionar uma regra de reconhecimento. Do ponto de vista histórico, a redação de regras até então não-escritas é uma das etapas que separa um sistema pré-jurídico de um sistema jurídico. O aspecto decisivo está no reconhecimento da referência ao escrito enquanto fonte de autoridade, isto é, como constituindo a maneira correta de resolver dúvidas relativas à existência da regra. Quando a força do escrito intervém, aparece uma forma elementar de regra (secundária) de reconhecimento permitindo identificar decisivamente as regras primárias.

Num sistema jurídico desenvolvido, as regras de reconhecimento são mais complexas. Em vez de identificarem as regras referindo-se exclusivamente a um texto ou código, também o fazem por referência a características gerais das regras primárias: seja o fato de sua promulgação por órgão específico, tal como (ato do) poder legislativo; seja que tenham determinada relação com decisões judiciárias, tais como sentenças precedentes a respeito de conflitos particulares. No primeiro caso, parafraseando o exemplo de Dworkin (1999: 42-3), é possível dizer que a proposição de que o limite máximo de velocidade nas auto-estradas do estado de São Paulo é 120 quilômetros por hora é verdadeira (melhor seria dizer correta) porque os legisladores que promulgaram a lei estavam no poder e porque o povo paulista aceitou, e continua aceitando, o sistema de autoridade usado nas Constituições estaduais e nacionais. Com relação à modalidade de identificação de regras que recorre a sentenças precedentes, pode-se ilustrá-la com a proposição de que o Estado deve indenizar os presos políticos discriminados e torturados durante a ditadura no Brasil como correta, porque a regra de reconhecimento aceita pelo povo brasileiro transforma as declarações dos juízes em direito.

O caráter estático do regime de regras primárias é vencido com regras de mudança. A forma mais elementar desse tipo de regra é a que habilita o indivíduo ou corpo de pessoas a introduzirem novas regras primárias para a regulação da vida do grupo ou de uma categoria de seus membros, eliminando assim as regras antigas. Tais regras possibilitam atividades como testamentos, contratos e transferências de propriedade, além de numerosas estruturas de direitos e obrigações criadas voluntariamente e típicas da vida jurídica. Essas regras que habilitam o indivíduo explicitam em linguagem jurídica a instituição moral que denominamos 
promessa.

O terceiro complemento introduzido no regime elementar das regras primárias, com a finalidade de remediar a ineficácia da pressão social difusa que o caracteriza, consiste, de acordo com Hart (1961: 94), em regras secundárias habilitando os indivíduos a resolver com autoridade a questão de saber se, em determinadas circunstâncias, uma regra primária foi transgredida. Denominamos regras de decisão às regras secundárias que conferem o poder de dividir as questões. Além de permitirem identificar os indivíduos chamados a julgar, tais regras estabelecem o procedimento seguido. Definem também um grupo de conceitos jurídicos importantes: juiz, tribunal, poder de jurisdição e poder de julgamento.

A articulação das regras primárias de obrigação e das regras secundárias de reconhecimento, mudança e decisão constitui a estrutura central de um sistema jurídico. Representa também instrumento extremamente fecundo para analisar grande parte das fontes de perplexidade tanto do jurista como do cientista político. É importante notar que a maior parte das dificuldades de compreensão e deformações que atingem os conceitos jurídicos - por exemplo, tomar a autoridade jurídica simplesmente como fato físico de comando e obediência habituais, esquecendo da questão da legitimidade $^{4}$, como faz a corrente positivista - provém do fato de que estes implicam uma referência ao que chamamos de ponto de vista interno ou do participante: a perspectiva daqueles que não se contentam em constatar e predizer o comportamento conforme as regras, mas que utilizam as regras como modelos que permitem avaliar seu próprio comportamento e o do outro.

Sob o regime simples das regras primárias, esse ponto de vista interno se manifesta em sua forma mais elementar: no fato de essas regras serem invocadas como fundamento de possíveis críticas, justificando

\footnotetext{
${ }^{4} \mathrm{Na}$ linguagem comum, o termo Legitimidade possui dois significados, um genérico e um específico. No seu significado genérico, Legitimidade tem, aproximadamente, o sentido de justiça ou de racionalidade (fala-se na Legitimidade de uma decisão, de uma atitude etc). É na linguagem política que aparece o significado específico. Neste contexto, o Estado é o ente a que mais se refere o conceito de Legitimidade. O que nos interessa, aqui, é a preocupação com o significado específico. Num primeiro enfoque aproximado, podemos definir Legitimidade como sendo um atributo do Estado, que consiste na presença, em uma parcela significativa da população, de um grau de consenso capaz de assegurar a obediência sem a necessidade de recorrer ao uso da força, a não ser em casos esporádicos. É por esta razão que todo poder busca alcançar consenso, de maneira que seja reconhecido como legítimo, transformando a obediência em adesão. A crença na Legitimidade é, pois, o elemento integrador na relação de poder que se verifica no âmbito do Estado. (Bobbio 1986)
} 
apelos à obediência, iniciativas de pressão social e penas para os infratores. Se acrescentarmos as regras secundárias ao sistema, então o campo daquilo que pode ser dito e realizado do ponto de vista interno se amplia e se diversifica bastante. Passa a compreender um conjunto de conceitos novos cuja análise requer referência ao ponto de vista interno: as noções de legislação, jurisdição, validade e, em geral, de poderes jurídicos privados e públicos. Antes de discutir o problema da legislação e a questão dos poderes privados e públicos, precisamos verificar como o direito lida com a realidade sociocultural complexa das sociedades contemporâneas.

\section{DUALIDADE E FUNÇÃO DO DIREITO MODERNO ${ }^{5}$}

Nas sociedades modernas, a complexidade vem acompanhada de uma variedade de formas de vida, isto é, de sua pluralização, além de uma individualização das histórias de vida. Em outras palavras, passa a haver inúmeras possibilidades de participar em diferentes grupos sociais e de construir uma história de vida específica, resultante de distintas inserções sociais. Em tal situação, diminuem os valores e convicções passíveis de unirem diferentes formas de vida. De modo que deixam de existir normas e crenças comuns unindo a sociedade como um todo.

A pluralização deu origem ao processo histórico-cultural que, desde Weber (1963), denominamos de desencantamento do mundo, processo a partir do qual os sujeitos sociais deixam gradativamente de compreender o mundo e a si mesmos com base em concepções religiosas. Consolida-se uma visão moderna de mundo sustentada culturalmente pelas esferas da ciência, moral-direito e arte. Com isso, explica Habermas (1987, I: 200-28), as questões de ordem cognitiva, normativa e expressiva se desligam das imagens religiosas de mundo e se desenvolvem segundo suas próprias lógicas internas: científica, moral-jurídica, e estética.

Assim, enquanto a pluralização e o desencantamento corroem os meios com os quais as comunidades poderiam auto-regular-se com base em crenças normativas e autoridades comuns, cresce em nossas sociedades uma ampla variedade de grupos e subculturas, com visões de mundo, valores e tradições próprias. Situação em que um número cada vez maior de conflitos, sobre diferentes questões, necessita de tratamento

${ }^{5}$ As próximas três partes retomam com muitas supressões e modificações seções do capítulo quarto da tese de doutoramento do autor (Schumacher 2000). 
por meio da obtenção de acordos explícitos, sob condições em que as bases para se alcançar tais acordos encurtam progressivamente. Espaços de vida anteriormente regulados por consensos implícitos passam a sofrer intenso questionamento, separando-se à medida que se intensifica o processo de racionalização da sociedade, isto é, de diferenciação entre questões de fé e questões científicas, entre questões de fé e assuntos que dizem respeito à justiça e à moralidade e entre questões de fé e julgamentos estéticos.

Além da pluralização e do desencantamento, cabe ainda acrescentar o fato de os processos de diferenciação social imporem, em nossas sociedades, uma multiplicação de papéis sociais, posições de interesse e tarefas funcionalmente especificadas. Essa diferenciação de funções na sociedade não só alcança um número crescente de esferas, como passa também a requerer dos próprios indivíduos a busca do sucesso individual.

Com base nessas considerações, podemos formular o problema da estabilização das sociedades modernas da forma como Habermas (1996: 26) propõe: a) como integrar socialmente formas de vida desencantadas, internamente diferenciadas e pluralizadas, se simultaneamente cresce o risco de dissenso, particularmente nas esferas de ação que se desligaram de autoridades sagradas e consensos implícitos? b) como obter estabilização num contexto em que a crescente necessidade de integração é pressionada por movimentos contrários, provenientes da economia capitalista - onde os agentes se orientam estrategicamente e decidem segundo seus interesses, observando condições de mercado - e das administrações - onde a estrutura hierárquica afeta a realização coordenada de metas coletivas. Esferas em que a coordenação social se realiza, ora por mecanismos anônimos de mercado que regulam/controlam as conseqüências da ação pelas costas dos atores, integrando-os sistemicamente através do dinheiro, ora através do poder.

Cabe ao direito moderno resolver problemas de coordenação social que surgem sob as condições acima descritas:

- onde a pluralização da sociedade fragmentou identidades e solapou crenças e convicções passíveis de produzirem consensos entre formas de vida diferentes;

- onde requisitos funcionais de reprodução material da sociedade, conduzidos pelo dinheiro e pelo poder, abrem a possibilidade dos indivíduos buscarem seus próprios fins num número crescente de espaços sociais. 
A solução está em limitar a necessidade de acordo a normas gerais demarcando e regulando áreas de livre arbítrio, através de: a) direitos e estatutos jurídicos que devem proporcionar algo como um ambiente social estável no qual as pessoas possam formar suas próprias identidades como membros de diferentes tradições e perseguir estrategicamente seus próprios interesses como indivíduos; b) leis que devem resultar de processos discursivos que as tornem racionalmente aceitáveis para pessoas orientadas em direção a compreenderem os argumentos umas das outras e a decidirem com base nas razões mais consistentes.

Para atores orientados por seu próprio interesse, todas as características da situação se transformam em fatos avaliados à luz de suas próprias preferências. Atores orientados ao entendimento se apóiam numa compreensão conjunta da situação e interpretam os fatos negociados à luz dos melhores argumentos. Contudo, se essas duas orientações esgotam as alternativas disponíveis para sujeitos que agem, então as normas adequadas para integrar socialmente e constranger interações estratégicas precisam lidar com duas condições contraditórias: a) apresentar restrições fatuais que modifiquem a informação relevante de maneira que o sujeito que age estrategicamente se sinta compelido a adaptar objetivamente seu comportamento à linha desejada; e b) simultaneamente, desenvolver uma força social integradora passível de impor obrigações aos destinatários - o que só é possível se as normas forem resultado de processos abrangentes de consulta, argumentação e deliberação social.

Considerando que esse tipo de norma requer concordância dos agentes, simultaneamente pela coerção e pela legitimidade, a solução encontra-se no sistema de direitos, que confere às liberdades individuais a força coercitiva do direito. Aspecto que a própria história parece confirmar, já que o núcleo do direito moderno é composto de direitos privados. Eles configuram o alcance legítimo das liberdades individuais e, por isso mesmo, são talhados à busca estratégica de interesses privados. Logo, como assinala Rehg (1996: XIX), o direito é um sistema de regras coercitivas e procedimentos impessoais envolvendo também um apelo a razões que, pelo menos idealmente, todos os cidadãos deveriam considerar aceitáveis.

Em filosofia, mas também na realidade constitucional das sociedades ocidentais, esse duplo significado do termo encontra correspondência na concepção de direito que se firmou gradativamente a partir das obras de pensadores como Locke, Rousseau e Kant. Os três consideram tanto o caráter positivo do direito coercitivo, que em certo sentido obriga pela ameaça, como também do direito que garante nossas liberdades. 
Também na linguagem cotidiana, a palavra direito é utilizada com duplo significado: como um sistema de regras (Constituição, código civil, código do consumidor, etc) que visa organizar a vida em sociedade, definindo o estatuto dos sujeitos e regulamentando suas relações sociais (políticas, econômicas ou familiares) e como prerrogativa de que dispõe cada indivíduo no contexto do sistema de regras, na medida em que reúne condições de aplicar uma dessas regras.

A dupla perspectiva das normas jurídicas, como leis da coerção e leis da liberdade, aparece com nitidez no caso dos direitos privados. Ao liberarem os motivos do comportamento conforme as normas, eles toleram uma atitude estratégica do ator em relação à norma, aquela em que o agente contraria a norma apostando que sua contravenção não será descoberta. Simultaneamente, enquanto elementos de uma ordem jurídica legítima, os direitos privados surgem revestidos de uma validade normativa, que supõe reconhecimento e convida os destinatários a segui-los pelo motivo não coercitivo do dever - o que sugere que uma ordem jurídica deve sempre possibilitar o cumprimento de suas regras independentemente do respeito à lei. Essa análise sobre o modo de validade do direito coercitivo também traz implicações para o processo legislativo.

Na medida em que os direitos de comunicação e participação política são constitutivos para a produção de regras legítimas, seu exercício por pessoas que agem simplesmente como sujeitos privados de direito civil é contraproducente. Tais direitos, ao contrário, necessitam de um comportamento comunicativo de cidadãos engajados. Assim, é razoável sustentar, como o faz Habermas (1996: 32), que o conceito de direito moderno já traz consigo a idéia democrática desenvolvida por Kant e Rousseau, de que a pretensão de legitimidade de uma ordem jurídica, construída sobre direitos, só pode ser resgatada através da força socialmente integradora da vontade unida e concordante de todos os cidadãos livres e iguais.

As leis de coerção devem comprovar sua legitimidade como leis de liberdade através do processo de legislação. Para fazer frente a essa dificuldade, não haveria senão duas possibilidades: ou a ordem legal permanece embutida numa ética social global subordinada à autoridade de um direito divino (caso dos Estados absolutistas de transição à modernidade); ou as liberdades individuais são complementadas por direitos de outro tipo - de cidadania, que não visam à escolha racional (do indivíduo isolado), mas à autonomia (Habermas 1996: 33). Pois, sem garantias religiosas ou metafísicas, o direito coercitivo forjado para o uso auto-interessado dos direitos individuais só pode conservar sua força socialmente integradora na 
medida em que os destinatários das normas jurídicas, em seu todo, puderem ao mesmo tempo se compreender como os autores racionais dessas normas.

Até aqui, estabelecemos que o direito moderno tem que se adequar, tanto às decisões descentralizadas de indivíduos orientados ao seu próprio sucesso em sociedades de mercado - logo aos requisitos funcionais da complexidade social -, como também manter uma base normativa possibilitando a ligação da justiça com procedimentos que apóiem sua legitimidade. Nos termos mais simples de Rasmussen (1994: 28), o direito integra a sociedade tanto pelo lado da coerção, como pela condição de possibilidade da implementação dessa coerção, a validade, que só pode ser derivada daqueles a quem se aplica. Qual das duas vai predominar em determinado momento ou deliberação, se coerção ou validade, é uma questão complexa: depende da cultura política da sociedade, do grau de difusão e qualidade da informação, da comunicação pública e das manifestações da opinião pública, do grau de empenho dos diretamente envolvidos no legislativo ou judiciário, dentre outros fatores. Talvez o uso do cinto de segurança em automóveis seja um bom exemplo de lei que conseguiu reunir coerção e validade, mobilizando os fatores mencionados. Podemos agora tratar da relação entre direitos humanos e soberania popular, abrindo caminho para conciliar autonomia privada com pública.

\section{DIREITOS HUMANOS E SOBERANIA POPULAR}

Os direitos humanos e o princípio da soberania do povo constituem as únicas idéias que podem justificar o direito moderno. As tradições políticas liberais concebem os direitos humanos como expressão da autodeterminação moral, enquanto as republicanas tendem a interpretar a soberania do povo como expressão da auto-realização ética. Na visão liberal, os direitos humanos se impõem ao saber moral como algo dado, ancorado num estado natural fictício; ao passo que na interpretação republicana a vontade ético-política de uma coletividade que se auto-realiza não reconhece nada que não corresponda ao próprio projeto de vida autêntico.

Enquanto os direitos humanos garantem aos indivíduos uma área de autonomia privada, ao abrigo das incursões do poder político, a soberania popular faz da vontade unificada do povo o fundamento da autoridade política e a garantia da autonomia pública dos cidadãos. Mesmo formando para a representação moderna da justiça um par indissociável, 
essas aspirações à autodeterminação moral das pessoas e à auto-realização ética dos grupos e comunidades, descrevem no interior das doutrinas do direito um paradoxo nem sempre reconhecido:

Em sua acepção liberal, a dominante [em nossos dias], os direitos humanos são geralmente definidos de maneira negativa em relação ao poder político, ao qual impõem limites intransponíveis, necessários para preservar a autonomia moral dos indivíduos e prevenir a tirania da maioria. A anterioridade dos direitos subjetivos sobre o contrato social é o argumento que permite repudiar toda a lei atingindo os atributos imprescritíveis da pessoa, cuja origem (sob a forma de direitos) é em si nãopolítica. Em sua expressão republicana, a soberania do povo é, ao contrário, concebida como a única fonte e instância de realização completa dos direitos individuais, cuja base é essencialmente política e comunitária, sendo que nenhum direito subjetivo poderia lhe pré-existir. (Langlois 1996: 311)

Para Habermas (1996), esse antagonismo deve ser atribuído à confusão na relação entre direito e moral que enfraquece a coerência teórica do direito. Pelo lado dos liberais, haveria a tendência de fazer a soberania popular depender de princípio moral racional anterior à emergência do político. Já, pelo lado dos republicanos, a igual dignidade dos indivíduos, enquanto membros do corpo social, derivaria da vontade geral.

Ao adotar o modelo da linguagem, Habermas (1996: 104) quer esclarecer a estrutura discursiva comum do direito e da moral, para mostrar que só uma validação intersubjetiva das normas jurídicas, que apela simultaneamente para a liberdade subjetiva dos indivíduos e para a autodeterminação democrática das comunidades, é capaz de conferir legitimidade ao direito positivo. No modelo proposto pelo autor, a co-originariedade da autonomia privada e pública se revela quando compreendemos o tema da autolegislação, segundo o qual os indivíduos são simultaneamente autores e destinatários de seus direitos. Tal enfoque possibilita compreender os direitos humanos como condições formais para a institucionalização jurídica dos processos discursivos de formação da opinião e da vontade, nos quais a soberania do povo assume um caráter vinculante, isto é, ligado por normas. Em outras palavras, são os direitos humanos que garantem a possibilidade de cada indivíduo atuar como sujeito autônomo livre e igual nos processos coletivos de discussão e decisão acerca das leis para todos. 
Assim, sem direitos humanos básicos garantindo a autonomia privada dos cidadãos, também não há como institucionalizar juridicamente as condições que permitem a esses cidadãos o exercício de sua autonomia pública. Conseqüentemente, as autonomias privada e pública se pressupõem mutuamente de tal modo que nem direitos humanos nem soberania popular podem pretender a primazia uma em relação à outra. Se quiséssemos dar mais importância a uma em detrimento da outra, nos defrontaríamos com uma dificuldade semelhante àquela da pergunta: quem nasceu antes, o ovo ou a galinha?

Logo, a relação interna entre autonomia privada e pública requer um conjunto de direitos abstratos, que os cidadãos devem reconhecer se quiserem regular sua convivência por meio do direito positivo legítimo. Esse "sistema de direitos" fundamentais - que cada regime democrático concreto deve elaborar e especificar, delineando as condições gerais necessárias para a institucionalização de processos discursivos no direito e na política - compreende cinco categorias amplas (Habermas 1996: 12223): (I) direitos a iguais liberdades individuais (subjetivas); (II) direitos relativos ao status de membro de uma associação voluntária de parceiros sob o direito; (III) direitos a proteção jurídica individual; (IV) direitos a iguais oportunidades de participação em processos de formação da opinião e da vontade, nos quais os cidadãos exercitam sua autonomia política e (através dos quais) criam direito legítimo; e (V) direitos a condições socioeconômicas e ecológicas de vida que garantam iguais oportunidades de utilizar os direitos civis elencados de (I) até (IV).

As três primeiras categorias garantem a autonomia privada dos cidadãos e estabelecem o código do direito, através do qual os cidadãos podem se confrontar como sujeitos jurídicos. $\mathrm{Na}$ ausência de tais categorias, não há como falar de direito legítimo. Ao reconhecer, na maior medida possível, os direitos fundamentais da pessoa sob a forma de uma liberdade subjetiva igual para todos (I), o código jurídico permanece poroso ou aberto às demandas sociais. Acompatibilização entre liberdades subjetivas e direitos subjetivos iguais permite formar um espaço público autônomo. $\mathrm{O}$ caráter abstrato e geral dessas liberdades individuais, que se choca com a necessidade do direito positivo encontrar aplicação no interior de limites de tempo e espaço, conduz à especificação de uma segunda categoria: os direitos fundamentais ligados ao estatuto de membro de uma comunidade jurídica livre (II). Por aí, os indivíduos que fazem parte de determinada comunidade recebem a garantia de que não serão excluídos arbitrariamente, podendo livremente emigrar e assim fugir àquelas leis jurídicas. 
Com esses direitos, institui-se também a distinção entre cidadão e estrangeiro, que deixa a determinação das regras de atribuição da cidadania, de acolhida dos refugiados e de ampliação da comunidade de direito nas mãos dos membros da associação jurídica. A terceira categoria, que completa os requisitos para o estabelecimento do código jurídico, assegura as condições para que pessoas e cidadãos possam exigir seus direitos. De maneira que cada um, ao se sentir lesado em seus direitos ou sofrer prejuízo, possa recorrer a uma arbitragem imparcial dos litígios, cuja decisão seja executável por todas as partes. A admissão de direitos judiciários, que estende igualmente a todos a proteção da lei (III), constitui um dos principais alicerces do universo jurídico moderno.

Enquanto condições necessárias de possibilidade, essas três categorias de direitos (de liberdade de expressão, de associação e de proteção jurídica) não devem ser entendidas como restrições à soberania do legislador, quer dizer, como direitos liberais fundamentais dirigidos contra o Estado. Constituem princípios jurídicos que orientam a estruturação das constituições. Só garantem a autonomia privada de sujeitos jurídicos, no sentido de que estes sujeitos se reconhecem reciprocamente em seu papel de destinatários de leis, concedendo uns aos outros um status sobre cuja base podem reivindicar direitos e fazer valê-los mutuamente.

A quarta categoria de direitos (IV) reconhece a todos e a cada um o poder de participar ativamente, em igualdade de oportunidades, da formação da opinião e da vontade comuns. Atribui assim à liberdade comunicativa o papel implícito de realizar a união entre os dois princípios normativos do direito moderno: enquanto a formação de uma vontade pública autônoma apela para a condição da autonomia privada, esta encontra naquela seu ponto de apoio indispensável. Isso significa que, no horizonte de um espaço público alimentado pelas contribuições dos cidadãos, cabe a eles mesmos definir as formas institucionais e jurídicas que a liberdade comunicativa deverá tomar. Portanto, ao fundamentar o status de cidadãos ativos livres e iguais, os direitos políticos capacitam os cidadãos a mudarem e expandirem seus diferentes direitos e deveres, de modo a interpretar e desenvolver simultaneamente suas autonomias privada e pública.

Por fim, a reconstrução dos direitos não esquece das condições materiais de existência necessárias à sustentação da democracia, cujo exercício permaneceria simplesmente formal se não incluísse as necessidades vitais dos indivíduos: a quinta categoria (V) reúne assim os direitos fundamentais a condições de vida sociais, técnicas e ecológicas compatíveis com o exercício igual para todos das liberdades anteriormente enunciadas. Tais 
direitos sociais devem ser tomados como princípios da vida democrática, elementos indispensáveis ao exercício das autonomias privada e pública, cuja expressão e sustentação não pode ser dissociada da garantia de condições socioeconômicas e ecológicas básicas.

É interessante não perder de vista o sentido de universalidade pretendido para esse sistema de direitos. Não se trata da especificação de um conjunto pré-dado de direitos naturais, mas de um esquema geral de direitos ainda não plenamente desenvolvido, que os sujeitos jurídicos têm que adotar como pressuposições, caso queiram regular sua vida em comum com meios do direito positivo. Assim, esse sistema de direitos constitui o meio jurídico mas não o fixa, permanecendo a necessidade de que ele seja desenvolvido de modo politicamente autônomo pelos cidadãos, no contexto de tradições e circunstâncias históricas específicas.

Após essas considerações, passemos à compreensão, no interior do modelo da comunicação, do Estado de direito e da democracia.

\section{PODER COMUNICATIVO E DELIBERAÇÃO}

Para entrarem em vigor e se tornarem coercitivos, os direitos necessitam de organizações que tomem decisões coletivamente vinculantes, isto é, que liguem o todo por meio de normas. Inversamente, essas decisões adquirem seu caráter coletivamente vinculante, graças à forma jurídica em que são forjadas. Dessa conexão interna entre direito e poder político, emerge a necessidade do Estado: de um poder de sanção, organização e execução. Em poucas palavras, "o Estado é o mecanismo que torna o sistema dos direitos e a coerção da lei permanentes" (Rasmussen 1994: 31).

À versão corrente, de que o Estado de direito garantiria apenas a autonomia privada e a igualdade jurídica dos cidadãos, Habermas (1996) contrapõe sua compreensão discursiva da inter-relação entre autonomia privada e pública. Contexto no qual o direito não recebe seu sentido normativo pleno, nem de sua forma, nem de um conteúdo moral a priori, mas de um procedimento de legislação que gera legitimidade. Pois, nesse nível de justificação, só conta como legítimo o direito que poderia ser racionalmente aceito por todos os cidadãos num processo discursivo de formação da opinião e da vontade.

Nessa abordagem do Estado de direito, observa Habermas (1996: 135), a soberania popular não se incorpora mais numa reunião de cidadãos autônomos identificáveis visivelmente, mas se volta para as for- 
mas de comunicação que circulam através de foros sociais e corpos legislativos. Dessa forma, o poder comunicativamente diluído na sociedade pode ligar o poder administrativo do aparelho estatal com a vontade dos cidadãos.

O poder do Estado se baseia na ameaça de sanções (apoiadas em instrumentos de força, como o poder de polícia) mas, ao mesmo tempo, é autorizado pelo direito legítimo. Independentemente de sua positividade, o direito reivindica validade normativa; já o poder está à disposição de uma vontade política como meio para a realização de objetivos coletivos, independentemente dos constrangimentos normativos que o autorizam.

Visto pelo prisma aqui adotado, o conceito de autonomia política abre uma perspectiva completamente diferente. Ao explicar que a produção do direito legítimo requer a mobilização da liberdade comunicativa dos cidadãos, coloca a legislação na dependência de outro tipo de poder, o poder comunicativo, que ninguém está realmente capacitado a possuir: "O poder surge entre os homens quando agem em conjunto, desaparecendo tão logo eles se dispersam". De acordo com esse modelo, inspirado em Hannah Arendt, um e outro, direito e poder comunicativo, têm sua fonte co-originária na "opinião em torno da qual muitos publicamente se uniram" (Arendt 1981: 213-14).

Por isso, essa linha de leitura da autonomia política envolve uma diferenciação no conceito de poder político. Para que as fontes de justiça das quais o direito extrai sua legitimidade não sequem, um poder comunicativo juridicamente gerado deve estar subjacente ao poder administrativo do governo. Por essa via, explica Rochlitz (1993: 51), Habermas reconstrói o conceito de Arendt no interior da tensão entre poder comunicativo (sinônimo de direito e legitimidade) e poder administrativo (sinônimo de busca estratégica de fins). Toma o uso público da liberdade comunicativa não só sob o aspecto cognitivo, da possibilidade da formação racional da opinião e da vontade, mas também do ponto de vista da força de motivação de convicções discursivamente produzidas e intersubjetivamente compartilhadas. Perspectiva na qual o uso público da liberdade comunicativa aparece também como gerador de potenciais de poder.

Habermas (1996) observa, então, que Arendt concebe o poder como o potencial de uma vontade comum formada numa comunicação sem coerções. $\mathrm{O}$ que lhe permite fazer uma oposição entre poder e violência, contrapondo a força realizadora da comunicação intersubjetiva, que busca o consenso, com a capacidade de instrumentalização da vontade alheia para fins próprios. O poder político aparece como a força que autoriza: se 
expressa por uma legislação que cria o direito legítimo, fundamentando as instituições, e se manifesta nos atos que fundam a liberdade, instaurando novas instituições e leis, protegendo a liberdade política e resistindo a formas ameaçadoras de repressão.

Com o conceito do poder comunicativo, no entanto, chegamos apenas à emergência do poder político, não ao uso administrativo do poder já constituído (ou ao processo de exercício do poder). Logo, em seu sentido pleno, o conceito de política também tem de incluir o uso do poder administrativo no interior do sistema político, bem como a competição pelo acesso a esse sistema. Como a constituição de um código de poder supõe que um sistema administrativo seja governado por autorizações para transmitir decisões coletivamente vinculantes, Habermas (1996: 150) propõe que se considere o direito como o meio através do qual o poder comunicativo é traduzido em poder administrativo. A idéia do Estado de direito pode ser então interpretada como a exigência de que o sistema administrativo, governado pelo código do poder, esteja amarrado ao poder comunicativo da legislação e mantido livre das intervenções ilegítimas do poder social (da força de interesses que podem se afirmar privilegiadamente).

Como um todo, a discussão dos princípios do Estado de direito converge para dois resultados gerais. Primeiro, para a noção de poder comunicativo que não deve ser entendido como se fosse a expressão (mais ou menos espontânea) de uma vontade comum, mas como o produto da sobreposição e interligação de uma variedade de discursos e formas de comunicação (mais ou menos institucionalizadas), baseadas em argumentos empíricos, técnicos, prudentes, éticos, morais ou jurídicos. Segundo, para a concepção de que "o exercício legítimo do poder (através do meio jurídico) só pode ocorrer se este permanecer ligado à sociabilidade comunicativa: o governo do povo deve ser o governo do Estado de direito, mas o Estado de direito deve estar ligado ao direito pelo povo" (Baynes 1995: 214).

Dessa relação entre poder comunicativo e Estado de direito, decorre uma concepção diferente de democracia, a deliberativa ou participativa. Isso porque, explica Manin (1987: 351), a fonte de legitimidade não é mais a vontade pré-determinada dos indivíduos, mas o processo de sua formação, quer dizer, a própria deliberação. Contexto em que uma decisão legítima não representa a vontade de todos, mas resulta da deliberação de todos. É o processo no qual a vontade de todos se forma, que confere legitimidade ao resultado, em vez da soma das vontades já formadas. Por isso, o princípio deliberativo é simultaneamente individualista e democrático. 
A força da democracia participativa aparece quando confrontamos sua compreensão dos papéis do Estado e da sociedade na ação política, com a visão defendida pelas correntes liberal e republicana. No modelo deliberativo, a política compreende mais do que o governo mínimo do liberalismo e suas variantes contemporâneas, que o restringem basicamente à preservação das condições de funcionamento da economia de mercado sob o Estado de direito. Por outro lado, significa menos do que a ação coletiva de uma sociedade política homogênea, a comunidade tal como é entendida pelo republicanismo.

Por esse novo modelo de ação política, comenta Rehg (1996: XXXI), só o Estado, enquanto sistema político investido do poder de decidir, pode agir. No entanto, sua ação só é legítima se os procedimentos formais do Estado de direito conservarem simultaneamente um caráter comunicativo ou discursivo, preservando, sob condições de complexidade, as fontes democráticas da legitimidade no público como um todo. Nessa abordagem da democracia, as condições para a formação racional da opinião e da vontade se transferem, do nível das motivações e decisões individuais ou de grupo, para o nível social de processos institucionalizados de deliberação e tomada de decisão. Nesse movimento, procedimentos democráticos e comunicações podem funcionar como filtros, selecionando questões e contribuições, informações e razões, de modo que só sejam consideradas aquelas relevantes e válidas.

É importante não perder de vista que essas considerações só se referem à perspectiva normativa ou ideal ligando Estado de direito e democracia. O processo democrático também se defronta com formas de poder social e com a complexidade das sociedades contemporâneas. A respeito dessas questões, as sociologias política e do direito não cansam de chamar à atenção para as diferentes estratégias empregadas por interesses sociais e organizações poderosas para utilizar o processo político em causa própria. Sugerem também que a complexidade funcional das sociedades contemporâneas não permite mais o controle democrático, mas só medidas administrativas indiretas orientadas pelo conhecimento de especialistas. Não há como negar essa realidade.

No entanto, a luta contra a dominação e pela emancipação não parece oferecer outro caminho, pelo menos até o momento, senão apostar no desenvolvimento do par de autonomias (privada e pública) e na reafirmação constante e renovada do processo democrático, pela introdução contínua de novos temas e desafios institucionais. No contexto do modelo deliberativo, boa parte das expectativas normativas, especialmente da 
gênese democrática da lei por meio do poder comunicativo, deve ser suportada por estruturas da sociedade civil e da esfera pública, ou seja, por associações, movimentos sociais e foros públicos.

Assim, as decisões tomadas em instituições formais de poder devem permanecer abertas aos impulsos provenientes de esferas públicas informais. Mais precisamente, segundo Habermas (1996: 374), abertas a uma rede complexa e ramificada de arenas culturais (internacional, nacional, regional e local) que se diferenciam pela densidade da comunicação, complexidade organizacional e alcance: dos públicos episódicos (bares, ruas etc), passando pelos ocasionais de eventos e apresentações particulares (manifestações, teatros, concertos etc), até a esfera pública abstrata de leitores, ouvintes e espectadores isolados, distribuídos ao longo de extensas áreas geográficas e reunidos através dos meios de comunicação de massa. Mesmo diferentes, esses públicos parciais permanecem, por meio da comunicação pública, permeáveis uns em relação aos outros. Essa permeabilidade pode ser ilustrada pelo exemplo dos movimentos operário e feminista que, ao longo dos séculos XIX e XX, empreenderam uma crítica de dentro ao discurso universalista da esfera pública burguesa, destruindo as estruturas que os constituíam como o outro.

Para desempenhar esse papel de canal de comunicação, a esfera pública não deve ser subvertida nem por grandes organizações poderosas, nem pela mídia. Do contrário, não poderá ligar discurso público e sociedade civil, possibilitando aos cidadãos identificarem questões sociais candentes e forçar sua consideração formal pelo sistema político. Enquanto agentes, podemos desempenhar esse papel em qualquer espaço social: na escola, no trabalho, na rua, em casa, nos jornais etc. Com razão poderíamos nesse momento indagar: por que deveríamos nos comportar assim, se é difícil e exige tanto esforço?

Porque os ideais constantes da idéia de democracia deliberativa fazem parte daquelas concepções normativas de agente racional, vida ética e conhecimento que não são simplesmente uma questão de escolha, mas que são constitutivas de nossa autocompreensão: (a) a noção de que cada um merece, em princípio, igual respeito como agente moral autônomo; (b) a noção de que a autonomia para raciocinar e argumentar é parte inestimável dos sujeitos sociais; (c) a noção da importância da publicidade, especialmente nas esferas do direito e da política; (d) ainda, a noção, subjacente às nossas considerações, de que não há padrões de autoridade independentes dos contextos histórico-culturais, os únicos que podem validar pretensões de conhecimento nas áreas científica, jurídica, política e moral 
- conhecimentos, é claro, sempre falíveis e passíveis de serem melhorados (Cooke 2000: 955). Por essas razões, temos o direito e o dever de lutar politicamente pelo que somos, quer dizer, por condições para nos desenvolvermos plenamente como sujeitos autônomos, individuais e coletivos.

\section{ALUISIO A. SCHUMACHER é professor de Ciências Sociais da UNESP - Campus de Botucatu.}

\section{REFERÊNCIAS BIBLIOGRÁFICAS}

ARENDT, H. (1981). A condição humana. Rio de Janeiro: Forense Universitária e Salamandra; São Paulo: Ed. Universidade São Paulo.

BAYNES, K. (1995). "Democracy and the Rechtsstaat: Habermas's Faktizität und Geltung". In: WHITE, S. K. The Cambridge Companion to Habermas. Cambridge (UK): Cambridge University Press, p. 201-232.

BOBBIO, N. e outros (1986). Dicionário de política. Brasília: Editora da Universidade de Brasília.

COOKE, M. (2000). "Five Arguments for Deliberative Democracy". Political Studies, v. 48, 947-969.

DAHL, R. A. (1989). Democracy and Its Critics. New Haven (Conn.): Yale University Press.

DWORKIN, R. (1999). O Império do Direito. São Paulo: Martins Fontes.

HABERMAS, J. (1987). Theorie de l'agir communicationel: Tome I: Rationalité de l'agir et rationalisation de la societé. Poitiers: Fayard.

HABERMAS, J. (1996). Between Facts and Norms: Contributions to a Discourse Theory of Law and Democracy. Cambridge (Mass.): The MITPress.

HART, H. L. A. (1961). The Concept of Law. Oxford: Oxford University Press.

HAYDON, G. (1999). "Morality in the Narrow Sense". Journal of Philosophy of Education, v. 33 , n. 1 , p. $31-40$.

HELD, D. (1987). Models of Democracy. Stanford: Stanford University Press.

LANGLOIS, L. (1996). "Habermas et la reconstruction rationnelle du droit". Dialogue: Canadian Philosophical Review, v. XXXV, n. 2, p. 307-326.

MANIN, B. (1987). “On Legitimacy and Political Deliberation”. Political Theory, n. 15, p. 351-377.

O’DONNELL, G. (1998). "Poliarquias e a (in)efetividade da lei na América Latina". Novos Estudos, n. 51, p. 37-61.

RASMUSSEN, D. (1994). "How is valid law possible?". Philosophy and Social Criticism,v. 20, n. 4, p. 21-44.

REHG, W. (1996). "Translator's Introduction". In: HABERMAS, J. Between Facts and Norms. Contributions to a Discourse Theory of Law and Democracy. Cambridge (Massachusetts): The MIT Press, p. ix- xxxvii.

ROBERT, P. (dir.) (1981). Le Petit Robert 2. Dictionnaire Universel des Noms Propres. Paris: S. N. L. - Le Robert.

ROCHLITZ, R. (1993). "De la Justice au Droit. Perspectives de la philosophie politique". Critique, t. XLIX, n. 548-549, p. 34-55.

SCHUMACHER, A. A. (2000). Comunicação e democracia: fundamentos pragmático-formais e implicações jurídico-políticas da teoria da ação comunicativa. 2000. Tese (Doutorado), Campinas, Unicamp. 
TAYLOR, C. (1985). "What is Human Agency". In: TAYLOR, C. Human Agency and Language. Cambridge, New York Port Chester, Melbourne, Sydney: Cambridge University Press, p. 15-44.

TAYLOR, C. (1989). Sources of the self: the making of modern identity. Cambridge (Mass.): Harvard University Press.

WEBER, M. (1963). "Rejeições Religiosas do Mundo e suas Direções". In: GERTH, H. e WRIGHT MILLS, C. (org.).Ensaios de Sociologia. Rio de Janeiro: Zahar Editores, p. 371-410. 